\title{
A STUDY OF ROLE OF NASAL ENDOSCOPY IN THE DIAGNOSIS AND MANAGEMENT OF EPISTAXIS
}

\author{
Arup Sen Guptaํ, Lopamudra Majumder², Shib Sankar Pal ${ }^{3}$ \\ ${ }^{1}$ Associate Professor, Department of ENT, MGM Medical College and LSK Hospital, Kishanganj. \\ ${ }^{2}$ Senior Resident, Department of Ophthalmology, MGM Medical College and LSK Hospital, Kishanganj. \\ 3Junior Resident, Department of ENT, MGM Medical College and LSK Hospital, Kishanganj.
}

ABSTRACT

\section{BACKGROUND}

Epistaxis is one of the most common emergencies in any ENT Department, which needs utmost attention and early intervention. If proper assessment on arrival of the patient is not done, a significant morbidity and mortality can occur.

\section{MATERIALS AND METHODS}

All epistaxis patients were subjected to nasal endoscopy under Local or General Anaesthesia on arrival in Emergency Ward. The most useful and definitive method to find out the bleeder in epistaxis is nasal endoscopy and electrocautery. A three-year retrospective clinical study of management of epistaxis with endoscopic cauterisation was done from July 2013 to July 2016 in the Department of ENT in MGM Medical College and LSK Hospital, Kishanganj, for 180 patients.

\section{RESULTS}

In most of the epistaxis patients, bleeding was controlled with nasal endoscopy and cautery successfully.

\section{CONCLUSION}

The study was conducted to establish the fact that the best way to manage epistaxis is by doing nasal endoscopy at the first outset to find out the bleeder and cauterise. It reduces cost, hospital stay and complications of nasal pack. Findings in our study for the site of bleeder will be a guide to the surgeon for successful control of epistaxis in a tense situation of active bleeding.

\section{KEYWORDS}

Epistaxis, Nasal Endoscopy, Management.

HOW TO CITE THIS ARTICLE: Gupta AS, Majumder L, Pal SS. A study of role of nasal endoscopy in the diagnosis and management of epistaxis. J. Evolution Med. Dent. Sci. 2017;6(16):1253-1255, DOI: 10.14260/Jemds/2017/272

\section{BACKGROUND}

Nasal bleeding is one of the most common emergencies in any ENT Department, which needs urgent attention and assessment to avoid morbidity and mortality. About $60 \%$ of general population experiences epistaxis in their lifetime and out of which around $6 \%$ seeks medical intervention. There are different ways one can manage epistaxis. Most common method of management of epistaxis is anterior and posterior nasal pack, where facilities like nasal endoscopy is not available. Apart from the high failure rate of $26 \%-50 \%$ reported in various series, nasal packing is associated with marked discomfort and several complications.(1) Electrocautery, arterial ligation of internal maxillary artery, anterior and posterior ethmoidal artery and external carotid artery in cases where all other measures fail are other methods of management. MGM Medical College and LSK Hospital, Kishanganj, is a Tertiary Care Institution which receives patients from Bihar, West Bengal and adjoining Nepal due to its geographical position. Amongst all patients in ENT Department and Emergency Ward, many of them are treated elsewhere with nasal pack. So many patients who

Financial or Other, Competing Interest: None.

Submission 02-02-2017, Peer Review 15-02-2017,

Acceptance 17-02-2017, Published 23-02-2017.

Corresponding Author:

Dr. Arup Sen Gupta

Orchid Resident,

\#35 Meghnand Saha Sarani,

Pradhan Nagar, Siliguri-734003,

West Bengal.

E-mail: drarupsengupta@yahoo.co.in

DOI: $10.14260 /$ jemds $/ 2017 / 272$ were referred from other Institutions were in critical condition with severe anaemia that needed early intervention. Although, predominantly a benign condition regardless of its aetiology, epistaxis can be severe, particularly in elderly and frail patients requiring hospitalisation and "aggressive" management. (2)

We realised in our study that the best way to manage an epistaxis is to go for meticulous nasal endoscopy at the outset. The availability of the nasal endoscope has been a boon to the otolaryngologist, since it not only helps in proper visualisation but also offers a direct mode of treatment to the area that is now accessible.(3) Probabilities of finding bleeder during active bleeding are the single most important steps in our study. We observed that finding the side of bleeding (right of left) is another determining point of success in our study, as bleeding never occurred from both sides. Patients can have bleeding from both sides on a later stage when blood travels via nasopharynx to other side of nose.

Each and every patient with epistaxis was resorted to nasal endoscopy under Local or General Anaesthesia on arrival. History of hypertension with any previous medication was noted down. Routine blood tests and blood group $\mathrm{Rh}$ were done. Those patients who were treated elsewhere with nasal pack were subjected to admission and then shifted to OT for nasal endoscopy. All patients whom we could not find out the bleeder are kept under observation and those who stayed nearby were asked to report when they rebleed. Few patients underwent Septoplasty to gain access to bleeding site. 


\section{Inclusion and Exclusion Criteria}

We included in our study all cases of epistaxis, which underwent successful nasal endoscopy and subsequent electrocautery to control bleeding. We excluded postoperative cases, tumour, bleeding diathesis, nasal trauma from our study. We also excluded patients who underwent arterial ligation, where bleeding could not be controlled despite repeated nasal endoscopy, which were 10 in numbers.

\section{MATERIALS AND METHODS}

A retrospective study was conducted of patients presented with epistaxis in the Department of ENT and Emergency Ward of MGM Medical College and LSK Hospital, Kishanganj for three years from July 2013 to July 2016. The study was conducted on 180 patients. History pertaining to hypertension, medication, previous history of recurrent bleeding was noted down.

Detailed nasal endoscopy and their findings, surgical methods like in-fracture of inferior turbinate to gain access underneath of inferior turbinate bleeder, septoplasty to reach out to bleeder posterior to deviation, recurrence, complications, hospital stay and blood transfusion were noted down. In addition, complete blood count, bleeding and clotting time, prothrombin time, blood group and $\mathrm{Rh}$ was done. Cases that underwent nasal endoscopy under GA were subjected to tests like urea, creatinine, ECG and Chest x-ray. A proforma including all these points were filled up in each case.

\section{Anaesthesia}

All cases of nasal cavity were packed with $4 \%$ xylocaine mixed with 1 in 10,000 adrenaline soaked cotton pledgets. Local Anaesthesia: 2\% Xylocaine with 1:100,000 adrenaline used for injectable.

\section{Demography}

Patients varied from 9 years and 86 years. Maximum cases (46) were from 51 to 60 years, that is $25.6 \%$ followed by 61 to 70 years' age group (28), that is $19.4 \%$. In one study of epistaxis of patients above 65 years showed a mean age of 73.51 years (range: 65 - 90 years).(4)

\begin{tabular}{|c|c|c|}
\hline Age & Number & Percentage \\
\hline $0-10$ & 2 & $3.6 \%$ \\
\hline $11-20$ & 17 & $9.4 \%$ \\
\hline $21-30$ & 10 & $4.3 \%$ \\
\hline $31-40$ & 28 & $15.6 \%$ \\
\hline $41-50$ & 26 & $14.6 \%$ \\
\hline $51-60$ & 46 & $25.6 \%$ \\
\hline $61-70$ & 35 & $19.3 \%$ \\
\hline $71-80$ & 14 & $7.8 \%$ \\
\hline $81-90$ & 2 & $3.6 \%$ \\
\hline \multicolumn{3}{|c|}{ Table 1. Age Distribution in Years } \\
\hline
\end{tabular}

Majority of the patients (136) were from rural areas, as this Institution covers a wide rural base.

\section{Sex Incidence}

Males were more frequently affected. In our study, 108 (60\%) cases were male vs. 72 (40\%) females. Males were affected nearly twice commonly as females.(5) Most of the studies showed males outnumbered females, as many studies included traumatic epistaxis in their studies where males were more.

\section{Seasonal Variations}

In our study, most of the cases presented during winter months November to March (112) vs. April to October (62). Different studies showed a significant increase in the incidence of epistaxis in the winter months ${ }^{(6)}$ due to adverse effect of dry weather on nasal mucosa supplemented by infection.

\section{Areas of Bleeder}

There is no clear definition of anterior epistaxis versus posterior epistaxis.(7) Our endoscopic findings showed that most of the bleeder arose from septum. Out of 77 cases of septal bleeder, 44 cases are from septal area anterior to middle turbinate and 29 cases are from posterior to middle turbinate, which is followed by bleeder below inferior turbinate.

\begin{tabular}{|c|c|}
\hline Septum anterior to middle turbinate & 44 \\
\hline Septum posterior to middle turbinate & 29 \\
\hline Below inferior turbinate anterior & 8 \\
\hline Below inferior turbinate posterior end & 52 \\
\hline Around middle meatus & 8 \\
\hline Anterior ethmoid area & 19 \\
\hline Sphenopalatine area & 12 \\
\hline Floor of nose & 8 \\
\hline Table 2. Endoscopic Findings - Areas of Bleeder \\
\hline
\end{tabular}

\section{Additional Surgical Measures other than Nasal Endoscopy}

We had to undertake 9 cases $(4.4 \%)$ of septoplasty to gain access to bleeder, as bleeder was found posterior to septal deviation. We did in-fracture of inferior turbinate to reach out to bleeder underneath of it for cauterisation in 60 cases (33.3\%).

\section{DISCUSSION}

Epistaxis is one of the most common emergencies in ENT Department and sometimes it becomes very challenging due to profuse bleeding and surgeon is at dilemma about the modalities of treatment.

In recent years, managing epistaxis with nasal endoscopy and cauterisation has helped patients from the discomfort of nasal packing and complications thereafter. The key to controlling most epistaxis is to find the site of the bleeding and cauterising with silver nitrate or bipolar diathermy. ${ }^{(8)}$ As nasal packing is a blind procedure, many of the time it is found that bleeding recurs after pack removal and surgeon does not have any other choice rather than repacking. This procedure causes extensive damage to nasal mucosa and synechiae, septal perforation, infection and sinusitis on a later stage. The failure of nasal pack is more in posterior bleeding.

Although, Hopkins rod was in place since half a decade, use of nasal endoscopy in the management of epistaxis is of recent origin. The nasal endoscope is a boon to the otolaryngologist, since it not only helps in proper visualisation of bleeding sites, but also offers direct and early proper treatment to an area that was once difficult to access. $(9)$ 
With nasal endoscope, we can directly visualise the bleeding sites in lateral wall crevices. With better understanding of nasal anatomy more and more surgeons are adopting and trying this method. Our study is only to strengthen this belief in nasal endoscopic cauterisation. This study tried to emphasise the finer points in managing epistaxis endoscopically with tricks of its success. This extensive study over a period of three years tried to find out the places where bleeder can be searched. These areas mentioned in our study are extremely helpful in detecting and controlling epistaxis.

In our study, most of the bleeding points were from septum (73) that is $40.6 \%$ and next was below inferior turbinate (60) that is $33.3 \%$. Inferior turbinates needed to be in fracture to gain access to the bleeder underneath it. We did $9(4.4 \%)$ septoplasty to gain access to bleeder posterior to deviation. In our study, maximum number of cases was in the age group of $51-60$ years (25.6\%) followed by $61-70$ years $(19.4 \%)$. One of the most important point this study highlights is that nasal endoscopy and cauterisation reduces patient's morbidity, hospital stay and cost of treatment. Most importantly failure rate is almost negligible if proper identification of bleeder can be done. Cryotherapy has the advantage of short hospitalisation (mean of 2.6 days) and low failure rate $16 \%$.(10) The use of bipolar rather than monopolar diathermy is recommended, as there are reports of optic or oculomotor nerve damage after the use of monopolar cautery close to orbit.(11) In our study we experienced two cases of recurrence of epistaxis within 7 days, which may be due to mistaken identification of bleeding point and it was managed successfully with repeat endoscopy. These two cases were previously treated with nasal pack elsewhere with lot of ulcerated mucosa. One case presented to us with a septal abscess, which was drained and managed.

In our study, we had given a lot of emphasis on hypertension. In all cases who presented with hypertension on admission, a detailed history of hypertension with medication was taken. It was found that those who were never hypertensive, their blood pressure drops after bleeding is controlled. We attribute this sudden increase in blood pressure to be transient in nature and were related to anxiety.

\section{CONCLUSION}

We summarise by few take home massages, which will certainly help the surgeons in managing epistaxis efficiently. 1) Epistaxis was always unilateral and detecting the side of epistaxis from history was the single most important factor.
2) Searching those areas as mentioned in our study helped us to detect bleeder at the earliest. 3) Best time of nasal endoscopy was during actual bleeding. 4) We need not prescribe anti-hypertensive medication for a newly detected hypertensive with epistaxis as many of them were transient in nature. 4) Role of anti-haemostatic drugs in controlling epistaxis was doubtful. 5) Never pack nose on arrival of patient, as it causes laceration of nasal mucosa and it may be difficult to find out bleeder on an injured mucosa. In conclusion, it can be said that the best way to manage an epistaxis is nasal endoscopic-guided cauterisation of bleeder.

\section{REFERENCES}

[1] Paul J, Kanotra SP, Kanotra S. Endoscopic management of posterior epistaxis. Indian J Otolaryngol Head Neck Surg 2011;63(2):141-4.

[2] Page C, Biet A, Liabeuf S, et al. Serious spontaneous epistaxis and hypertension in hospitalized patients. Eur Arch Otorhionolaryngol 2011;268(12):1749-53.

[3] Kumar VMV, Prasad RKU, Gowda BPR, et al. Rigid Nasal Endoscopy in the Diagnosis and treatment of Epistaxis. J Clin Diagn Res 2013;7(5):831-3.

[4] Yüksel A, Kurtaran H, Kankiliç ES, et al. Epistaxis in geriatric patients. Turk J Med Sci 2014;44(1):133-6.

[5] Sengupta A, Maity K, Ghosh D, et al. A study on role of nasal endoscopy for diagnosis and management of epistaxis. J Indian Med Assoc 2010;108(9):597-8, 600-1.

[6] Purkey MR, Seeskin Z, Chandra R. Seasonal variation and predictors of epistaxis. Laryngoscope 2014;124(9):2028-33.

[7] Rudmik L, Smith TL. Management of intractable spontaneous epistaxis. Am J Rhinol Allergy 2012;26(1):55-60.

[8] Dudia A, Jaiswal V, Jones NS. Guidelines for the management of idiopathic epistaxis in adults: how we do it. Clinical Otolarymngology 2008;33(6):618-20.

[9] Babu MM, Gowda B, Satish HS. Role of rigid nasal endoscopy in the diagnosis and management of epistaxis. IOSR Journal of Dental and Medical Sciences 2014;13(3):40-5.

[10] Varshney S, Saxena RK. Epistaxis: a retrospective study. Indian Journal of Otolaryngology and Head and Neck Surgery 2005;57(2):125-9.

[11] Pope LER, Hobbs CGl. Epistaxis: an update on current management. Postgraduate medical Journal 2005;81(955):309-14. 